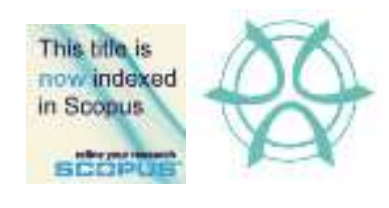

\title{
PUBLIC SPACES AND GENDER: TESTING THE RELATIONSHIP OF SPATIAL CONFIGURATION OF STREET NETWORKS
}

\author{
Nurul Shakila Khalid ${ }^{1}$, Raja Norashekin Raja Othman ${ }^{2}$, and \\ Marlyana Azyyati Marzukhi ${ }^{3}$ \\ ${ }^{1,2,3}$ Centre of Studies for Town and Regional Planning, \\ Faculty of Architecture, Planning and Surveying \\ UNIVERSITI TEKNOLOGI MARA, MALAYSIA
}

\begin{abstract}
The purpose of this paper is to examine the spatial dominance in public spaces from a gendered and women perspectives and to analyse the relationship with the spatial configuration of street networks. In analysing the street networks in Space Syntax, the question arises; to what extent the movement and activity may explain street integration among gender-based pedestrians. The result found that there is a correlation between spatial configurative analyses and women present in the streets. In essence, the less integrated streets attract more women pedestrians and improve better quality of space. The research is relevant to spatial design interventions and policymaking to enhance gender-equal access to public space.
\end{abstract}

Keywords: Spatial Dominance, Gender, Space Syntax, Public Space

${ }^{1}$ Lecturer at UiTM. Email: shakilakhalid@uitm.edu.my 
PLANNING MALAYSIA

Journal of the Malaysia Institute of Planners (2020)

\section{INTRODUCTION}

A shared vision in the New Urban Agenda (NUA) for a sustainable future that emphasizing all people have equal rights, opportunities, and access to the benefits that cities can offer. In other words, the shared vision of NUA refers to the inclusivity. It ensures that all inhabitants, without discrimination of any kind, can produce safe, accessible, healthy, resilient, affordable, and sustainable cities and people to foster quality of life for all. Inclusivity or equality implies that women enjoy urban public life in the fullest dimension as men. Although the idea of the right to the city introduced by Henri Lefebvre is manifested by existing social inequalities of religion, race, ethnicity, or class, above all, equality is a layer of gender inequality. Economic, cultural, and social norms shape gender roles and said that women and men experience cities in different ways. It also undermines their right to public space; therefore, their right to the city can be understood where everyone has an equal right and access to the city and its public spaces (UNHabitat, 2010).

For the sake of diversity and spatial justice, it is essential that women feel safe, welcoming, and comfortable in public spaces as they provide great opportunities to engage in economic, physical, and social activities. Ever, street avoidance, safety or uneasiness, especially for women, become a concern especially female employment has increased in past decades that resulted in women have had a strong presence in public spaces and make them be a part of urban life (Mehta, 2013; Tandogan and IIhan, 2016; Beebeejaun, 2017). Indeed, women have reported that they are likely to experience public hassles and incivilities and be in the streets or public spaces. These studies have found the similar findings that assess street use by gender have identified women are often not quite half the users, as eloquently quoted by Souza et al., (2018). Women feel unsafe and absent in public spaces because of several factors such as the perception of safety, poorly maintained buildings, society's behaviour, strangers, crime hotspots, poor streetscape, and economic discrepancy (Tandogan and Ilhan, 2016; Arjmand, 2016).

On the other hand, other scholars criticize the importance of putting the gender-specific needs and accommodating the needs of women in urban spaces. However, attending to the needs of women in the public space lends itself to an entirely different discourse within urban planning. This discourse is often shaped around a religious belief or an ideology to legitimize the segregation of the public space across the gender line. Mostly informed by traditional and cultural values, such arguments are usually enforced by concerns over the safety of women in the public space, maintaining the exalted position and dignified role of women to nurture the society (Doan, 2010) morally. In Islamic theocracy, the practice and implementation of gender-segregated public spaces is not the sole instance. It is perhaps the most contested one. On the notion of respecting the needs of women in public, the Sharia law is being utilized to institutionalize the urban policies 
Nurul Shakila Khalid, Raja Norashekin Raja Othman, Marlyana Azyyati Marzukhi

Public Spaces and Gender: Testing the Relationship of Spatial Configuration of Street Networks

based on the segregation of sexes. Whereas gender segregation has always existed as part of the culture and belief in the Muslim context, the comprehensive effort to implement such a divide is a rather recent phenomenon.

Several feminist geographies have examined the complex ways that gender articulated through spatial practices in urban spaces. One of the spatial methods, movement across space, reflects the interrelation between available resources and social identities to construct gender identities (Beebeejaun, 2017). However, few studies examine the safety, needs, and activities that occur in urban public spaces related to the gender composition with space (Arjmand, 2016; Khalili et al., 2015; Souza et al., 2018). The current study addresses these limitations and fills a gap by counting women and men on streets that differ in space use (Beebeejaun, 2017 and Francis, 2016). As a result of this line of reasoning, two (2) questions were raised; (i) what the effects of gendered power relations to the women's rights to the city are? (ii) to what extent spatial configuration measures the success of the street as a public space for all. This study indeed contributes to the literature by offering insightful knowledge of how spatial configuration may affect the pedestrian's everyday experience, activity, commitment to the city they live in, and social interaction by analysing how they use the space effectively.

The paper begins by comparing the narratives of women and men living in the multi-ethnicity city, which helps expose the multi-layered nature of gendered belonging constructed in daily urban practices. It then analyses the spatial configuration of street networks and their relationship with equal access to public spaces. The discussion thus explains on gendered use in the street and the proportion of pedestrians by gender. Lastly, the paper discussed the importance of spatial design and policymaking in urban spaces for all and the practicality of the right to the city and in solving user needs and aspirations in public spaces.

\section{REVIEW OF RELATED LITERATURE}

Why gender matter? Gender is a set of societal expectations for behaviour, not an essential quality or a fixed role (UN Habitat, 2010). Gender policies began to be integrated into public policies following the World Conference on Women in Beijing in 1995 and strengthened with the Treaty of Amsterdam in 1999. Later, the Handbook for Gender-Inclusive Urban Planning and Design promotes planning and design with a gender perspective that actively incorporates the voice of women, sexual, and gender minorities. With pioneered strategies to plan and build cities for women since the early 1990s, Vienna required each of its agencies to introduce strategic plans and initiatives to support the explicit inclusion of needs and lived experiences of women to shape more equitable policy outcomes people regardless of genders. The issue began when the researchers found that $75 \%$ of the park usage are the boys. It happened because the park designed only 
for the boys, and they dominated park areas like basketball courts and playground equipment, leave the girls behind. Also, a study at public housing in Kuala Lumpur found that female respondents were physical less active in carryout exercise as compared to male (Ling et al., 2018). The scenario thus supported by Sassen (1996), an urbanist that said, the practice of urban planning and design and its outcomes are not gender neutral. Inequality is spatially reinforced by design, from the systems down to individual public spaces. Female's needs are different than male especially in the issue of security. For instance, a study at Petaling Jaya found that female is more easily affected by the feeling of unsecured and threatened by the presence of foreign immigrants in their residential area (Ling et al., 2017).

In explaining the relationship between spatial configuration and gendered-space for women pedestrian, the literature provides an understanding of gender-based accessibility to public spaces as the social and political structures of society (Mehta, 2013). In the western world, historically, public spaces were designed predominantly to serve white, working men, while private spaces were associated with women. A spatial dichotomy based on a differentiation of female and male and their functions in the public space has served as the underpinning of the spatial arrangement of modern cities today. The city accurately embodies, among other things, the historical gender division of labour within a normative society structure. Gender relations are implicated in our culturally constructed identity, where it is sanctioned that man should dominate space, and women's assigned place is in the house (Goodsell, 2003). This supports by Arjmand (2016) that the status differential between women and men creates specific urban spatial configurations related to the patriarchal spatial institutions that reinforce the dominance of men. He adds that the social system in place, through institutions of socialization, provides advantages to men that are denied to women. When spatial institutions are conceptualized and controlled by men, the space within which they operate can be unfair in their favour and against women, making them effectively gendered (Doan, 2010). Hence, women's lives in urban spaces are shaped by the visible and invisible boundaries created by social structures. According to Beebeejaun (2017), discrimination toward women who do transgress the spatial binary and enter public spaces must contend with an internalized fear of male violence. Women who come male-dominated public spaces may be subject to a wide range of verbal and physical harassment for transgressing the established boundary. Furthermore, other individuals whose identities reflect marginalized categories, such as race or sexual identities, also encounter this highly gendered spatial system and may feel exceptionally constrained in the ways that they may express themselves in public spaces controlled by the dominant command of power (Beebeejaun (2017). 
Nurul Shakila Khalid, Raja Norashekin Raja Othman, Marlyana Azyyati Marzukhi

Public Spaces and Gender: Testing the Relationship of Spatial Configuration of Street Networks

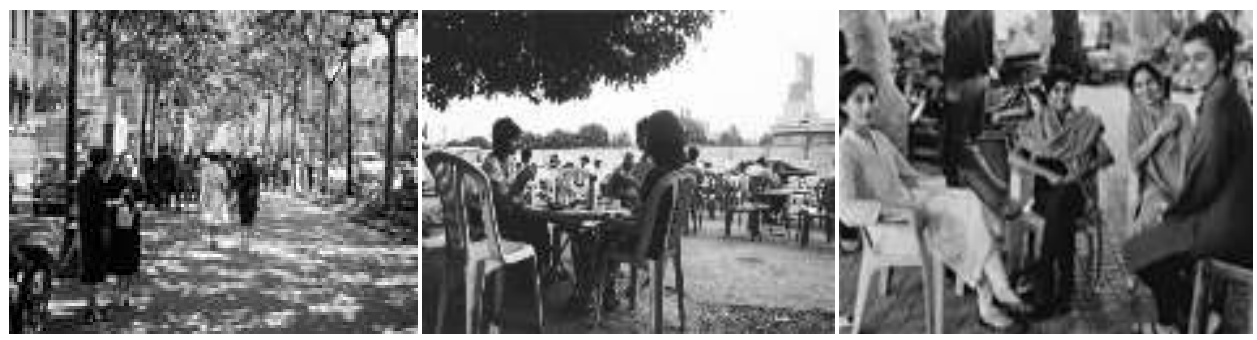

Figure 1: The notion of gendered space in understanding their needs and behaviour has been concern in urban planning since 1940s. (Source: Arjmand, 2016)

\section{BACKGROUND OF STUDY AREA}

Petaling Street and Kasturi Walk were performing the role of a pedestrian shopping street among locals and tourists. When one thinks of the colourful street and cultural street, Petaling Street come to mind before others. Petaling Street or also known as Chee Cheong Kai means Starch Factory Street in Cantonese, referring to its history as the centre for the production of tapioca flour back then. Petaling Street was established and active since the mid-19th century Petaling Street was paved with red tiles and covered with a dragon-like canopy that keeps out the sun. With a wet market in the early morning, Petaling Street is one of the most famous imitations of "branded" items, selling various traditional foods, vegetables, trade, and presenting the public life in Kuala Lumpur. While Kasturi Walk is a covered and open-air flea market set along Jalan Kasturi, a street along with Kuala Lumpur Central Market, a historical craft centre. There are over 20 wooden kiosks with coconut leaves (to enhance the feeling of being in a kampung), and food stalls sell traditional Malaysian mouth-watering sweets and traditional food.

The reason for choosing these two streets is because they reflect contrasting images and symbolism of different ethnics whereas Kuala Lumpur is a city for people of diverse identities, especially in the light of its image for Muslims, Chinese, and Indians. Besides, this is the only pedestrianisation street in Kuala Lumpur, a car-free street to create more space for pedestrians and indulgences by the co-presence of the attractors, such as the street malls and buskers, street vendors, cultural performance, and wide pathways. This would contribute to the research idea to examine the space dominant in public spaces. 

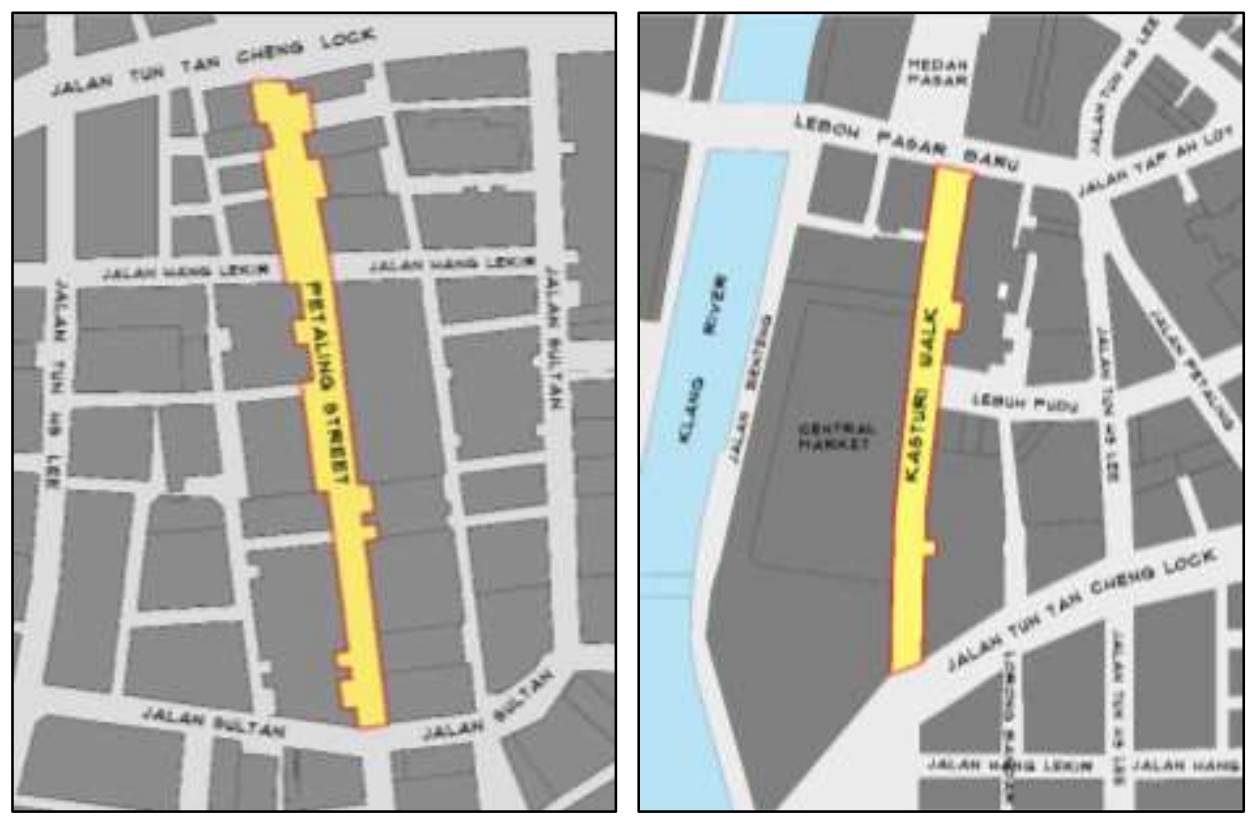

Figure 2: The Map of Petaling Street (left) and Kasturi Walk (right), Kuala Lumpur

\section{METHODOLOGY}

Space Syntax is a method that consists of calculating configurative spatial relationships in built environments and measuring the accessibility of all parts of a network under consideration from each element. Developed by Bill Hillier and Julienne Hanson in the 1970s, Space Syntax explains the relationship between a spatial pattern and human behaviour (Hillier and Hanson, 1989). Besides, configurational analyses and observational studies of cities have revealed that the spatial layout design includes the length, connectedness, and position occupied by each route of movement within the gridded system will influence the density of human movement and activities that occurs along with (Crucitti et al., 2006; Hillier, 2007). This theory explains that integration is a powerful predictor of how "busy" or how "quiet" a street activity is likely to be.

The significance of spatial networks in affecting the pedestrian activities and movement has been addressed through the framework of configurational analysis of Space Syntax (Hillier et al., 1993). Since pedestrian accessibility occurs according to the fine grain of the environment and to its city larger-scale structure, appropriately discriminating measures of street networks are critical for designing the street for equal accessibility. Indeed, several factors include spatial configuration, the attractions of co-presence, pathway infrastructures, and pedestrian comfort are essential to the accessibility measures 
Nurul Shakila Khalid, Raja Norashekin Raja Othman, Marlyana Azyyati Marzukhi

Public Spaces and Gender: Testing the Relationship of Spatial Configuration of Street Networks

for street's inclusivity. Through describing and exploring the activity patterns, and experience among women and men pedestrians, this research, therefore, employs qualitative and quantitative data collection as empirical evidence; the snapshot observations, activity mapping and the application of space syntax to measure the relationship between street networks and how different gender experience and interact within the spaces. Recently, space syntax is used as a powerful analytical tool in architecture and urban planning. Space syntax is best described as a research program that investigates the relationship between humans and space from diverse forms such as buildings, settlements, cities, and landscapes (Bafna, 2003).

The space syntax theories have described the dynamism of social life and movement within spaces, and this is achieved through the axial map. The axial map is initially constructed to describe the urban areas in which the structure of its street network could be explained as a discrete spatial configuration (see Figure 3). The longest lines passing down streets are considered as nodes and their intersections as links in the graph. This is characterised in space syntax as the level of integration. The relationship of each axial line and integration values examined to measure the connectivity of each line in an axial map. Integration is an indicator of how easily one can reach a specific line of the axial map (Hillier et al., 1993; 2007). Integration measures the mean depth of every axial line. For this study, the researcher employed two parameters in space syntax; local integration (micro-level) and global integration (the entire streets system). For the global integration of analysis, space syntax takes into consideration every possible relationship in the system - from anywhere to anywhere, while local integration analysis measures a particular local catchment area as three steps from the primary line. To achieve the research aim, analysis of two shopping streets was done within a $3 \mathrm{~km}$ radius for vehicle and pedestrian. 


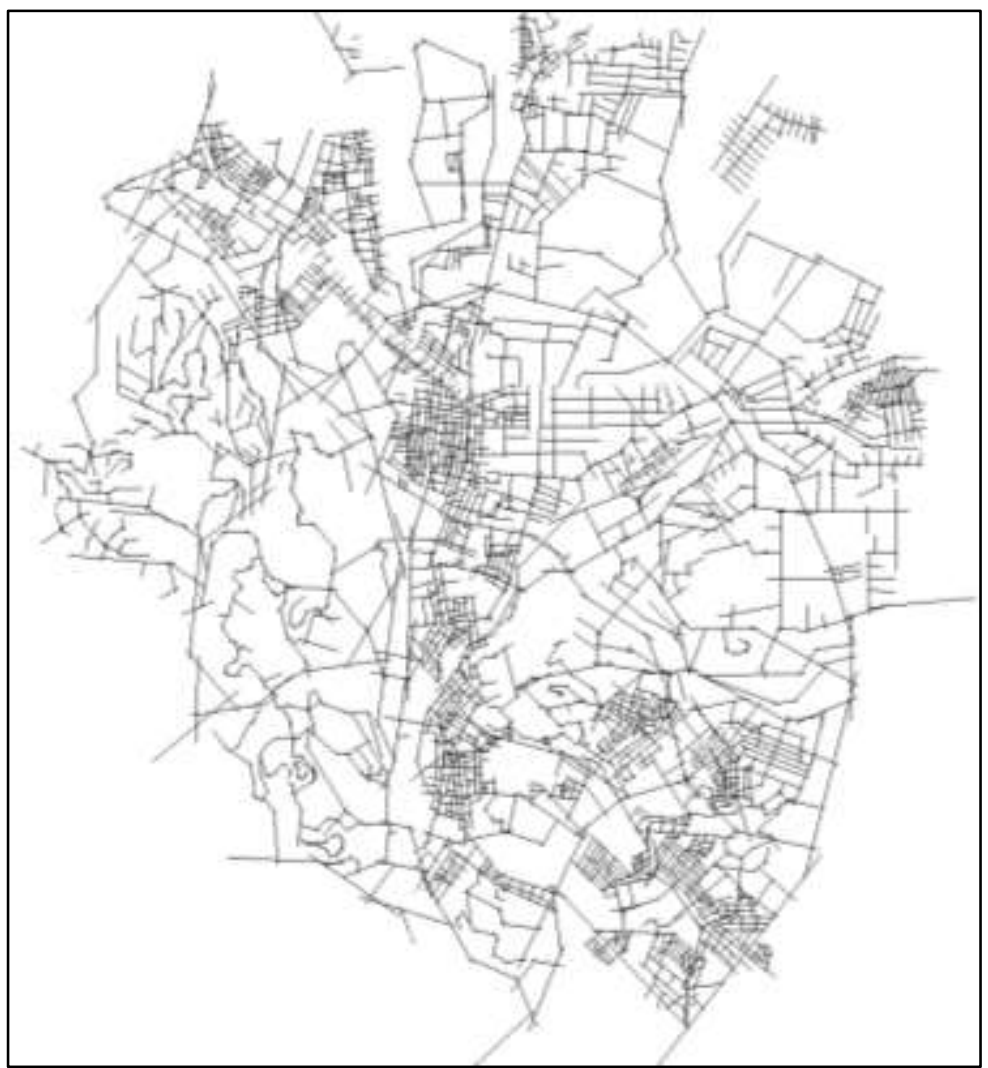

Figure 3: The Axial map consists of 2,437 street segments that were audited in the DepthMap software

The snapshot observation records and measures individual and stationary activities such as talking, eating, shopping, taking a photo, walking, smoking, and participating in social activities and the number of pedestrians in Petaling Street and Kasturi Walk. This direct observation organized by recording where and how people occupy and use public spaces through field notes, photographing, and mapping.

The observation was scheduled for typically busy daylight times spread out on weekdays and weekends (weekdays $8.00 \mathrm{am}$ to $8.15 \mathrm{am}, 1.00 \mathrm{pm}$ to 1.15 $\mathrm{pm}$ and $5.00 \mathrm{pm}$ to $5.15 \mathrm{pm}$; weekends $12 \mathrm{pm}$ to $12.15 \mathrm{pm}$ and $5.00 \mathrm{pm}$ to 5.15 $\mathrm{pm}$ ). The observations included (i) tracking number of people, (ii) duration of stay, and (iii) social activities engaged in the streets. Each observation was 15 minutes long to address the problem of observer fatigue. The literature studies of human activities and behaviour in public spaces showed that the duration of activities recorded in five-minute intervals. During the observation, the 
Nurul Shakila Khalid, Raja Norashekin Raja Othman, Marlyana Azyyati Marzukhi

Public Spaces and Gender: Testing the Relationship of Spatial Configuration of Street Networks

researcher acted as a participant-observer using the businesses and street space in the study areas. The researcher stands in the intersection in the centreline of the streets to record the social activities and count the number of pedestrians encountered using field notes. Besides, the research also applied photographs to record pedestrian behaviour patterns and to verify the data collected. Pedestrians communicating with each other or engaged in everyday activities indicated as a group.

\section{ANALYSIS AND FINDINGS Analysis of spatial configuration}

Spatial configuration was analysed using space syntax by assigning syntactic values to every street segment in the system and produced the axial map. The axial map is a network of intersecting axial lines. The axial map is represented by the longest lines of sight and the fewest to characterize every street segment in Kuala Lumpur. Two (2) analyses conducted to read the pattern of activities and movement among women and men pedestrians in Petaling Street and Kasturi Walk - to observe how people use and move within space (Hillier and Hanson, 1989). The first analysis was a global measurement $(\mathrm{R} n)$, which helped observe the relationship between each axis and all other axes, and to show the degree of integration. The secondary analysis was a local measurement (R3), which helped identify an axis's relationship with its connected axes (up to three steps away). Local integration is the default indicator for human movement, as Hillier stated that people tend to take paths that minimize trip length or maximize trip effectively. This paper refers to space/spatial as street and pedestrian paths of Kuala Lumpur (see Figure 3). The axial map developed to represent the spatial configuration of the street and pedestrian pathway network. The pedestrian network includes all alleys, paths, and pedestrian-only lane.

The spatial layout pattern within the $3 \mathrm{~km}$ radius shows that almost $80 \%$ of the area consists of a higher density of streets, which refers to the vehicular movement in urban areas. For example, Jalan Tun Tan Cheng Lock, Leboh Pasar Baru, Lebuh Pudu, and Jalan Hang Lekir dominated by vehicles that largely contributed to the traffic congestion. The concentration or integration cores can be traced easily by looking at the street network, whereas the nucleus centre happened along the major road in the city centre (Hajrasouliha and Yin, 2015). The layout patterns of Kuala Lumpur are semi-regular grid to very gridiron a nonuniform of distribution of land uses ever since 1896 when Kuala Lumpur became the capital of Malaysia after Selangor. Historically, the British were the most influential western colonialists and adapted the urban gridiron patterns when colonized Tanah Melayu circa the 1800s. It can be seen that the urban morphology of Kuala Lumpur was according to geographical condition and developed along the river as the primary sources of life-transportation and sanitation. 
Integration has analysed to measure the accessibility of the spatial layout pattern, from the very grid with mainly linear through streets to the fewer grids and form a deformed grid at a larger scale. The integration values in space syntax represent global and local integration value of Petaling Streets and Kasturi Walk, as represents in Table 1. Street integration can be calculated by considering all other streets in the network (global) or by limiting the calculations to streets within a certain distance (local).

Table 1: Syntactical values of Petaling Street and Kasturi Walk for pedestrian path networks compared to other streets.

\begin{tabular}{|l|c|c|c|}
\cline { 2 - 4 } \multicolumn{1}{c|}{} & $\begin{array}{c}\text { Global } \\
\text { Integration } \\
\text { (Rn })\end{array}$ & $\begin{array}{c}\text { Local } \\
\text { Integration } \\
\text { (R3) }\end{array}$ & Connectivity \\
\hline Petaling Street & $\mathbf{0 . 8 2 3}$ & $\mathbf{2 . 8 9 1}$ & $\mathbf{9}$ \\
Kasturi Walk & $\mathbf{0 . 8 9 8}$ & $\mathbf{2 . 6 9 7}$ & $\mathbf{6}$ \\
Jalan Benteng & 0.875 & 1.666 & 5 \\
Jalan Tun Tan Cheng & 0.823 & 2.833 & 16 \\
Lock & 0.825 & 2.938 & 11 \\
Jalan Hang Lekir & 0.735 & 2.799 & 18 \\
Jalan Sultan & 0.986 & 2.636 & 18 \\
Leboh Pasar Besar & 0.911 & 2.469 & 11 \\
Jalan Tun Tan Siew & 1.141 & 3.098 & 22 \\
Win & 1.022 & 2.402 & 13 \\
Jalan Tun Perak & & & \\
Jan Tun HS Lee & & & \\
\hline
\end{tabular}

According to Table 1, the streets can have a high local but low global integration value and vice versa, such as Jalan Benteng and Jalan Tun HS Lee. Jalan Benteng is a fully pedestrianized street, whereas Jalan Tun HS Lee, 4-lanes road primarily dense with the vehicles. Petaling Street and Kasturi Walk scored 0.823 and 0.898 for the global integration value - average integration value at the city scale as the semi-open street space. Principally, the higher the integration value of a street, the lower the number of axial lines needed to reach that street, and the high number of pedestrians and car movements. The highest global integration streets are Jalan Tun Perak (1.141), Jalan Tun HS Lee (1.022) followed by Leboh Pasar Besar (0.986) and Jalan Tun Tan Siew Sin (0.911), which the streets cater to more movements of vehicles and add to the higher street density (see Figure 4). Jalan Tun Perak specifically is a long-stretched street of $810 \mathrm{~m}$ with $23 \mathrm{~m}$ of width that attached to Jalan Pudu and highly visual connected to other adjacent streets such as Jalan Tunku Abdul Rahman, the infamous shopping street among locals. Leboh Pasar Besar and Jalan Tun Tan Siew Sin also move the vehicles and the buses, which may be accessed with the least number of turns from all other lines. These streets are accessible to pedestrians, 
Nurul Shakila Khalid, Raja Norashekin Raja Othman, Marlyana Azyyati Marzukhi

Public Spaces and Gender: Testing the Relationship of Spatial Configuration of Street Networks

but due to the poor pathway infrastructures, complex connectivity to the transit stops, and higher traffic volume, pedestrian attempts to avoid using the streets. Although the higher integration of the streets indicates the success of space, it doesn't happen to the streets due to adopted of the car-centric street design as the case in Malaysian cities.

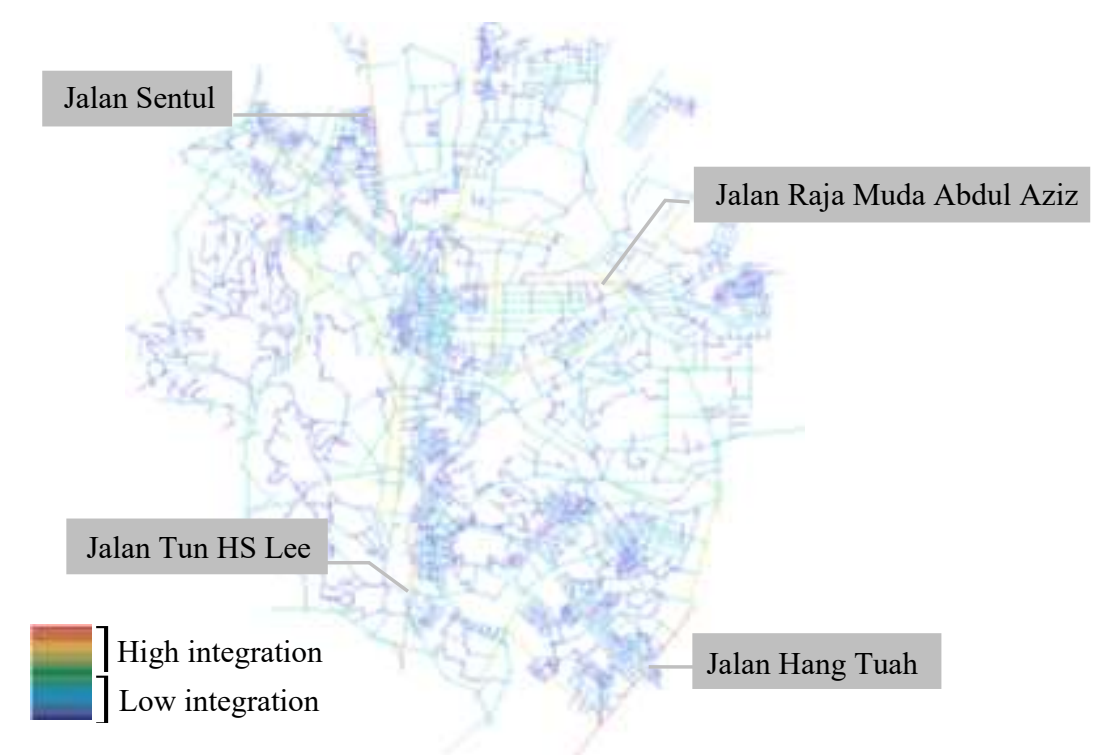

Figure 4: The red lines show the four streets with highest global integration values

The results of local integration displayed a range of colours from the red lines as the most integrated streets through to the blue lines as less integrated streets. The axial lines with the highest local integration value are the lines that are accessible with the least number of connections from other lines in its surrounding. The most integrated locally is Jalan Tun Perak (3.098), followed by Jalan Hang Lekir (2.938) and Petaling Street (2.891), while the lowest integration value is Jalan Benteng (1.666) and Jalan Tun Tun HS Lee (2.402). The more integrated streets require fewer turns to reach the segment from other streets and are considered to be more accessible. According to the space syntax principle, streets that had low integration values were safer and accessible by the pedestrian as it has proved that Jalan Benteng is fully accessible by pedestrian-only as the street is closed from the car to access and thus improved the quality of space for people to use the space. While the local integration values for Petaling Street and Kasturi Walk are average amongst the other streets intersect-segregated, it can be said that both streets are pedestrianized-attracting the presence of pedestrians because of the presence of commercial activities along with them. 
Connectivity gives the number of lines that are directly connected to a specific line. According to Figure 6, the high levels of connectivity are Jalan Tun Perak (22), Jalan Sultan (18) and Leboh Pasar Basar (18). While Petaling Street (9) and Kasturi Walk (8) along with Jalan Benteng (5) are low connectivity compared to other streets with $300 \mathrm{~m}$ and $220 \mathrm{~m}$ of the street length. The low street connectivity shows the streets have low exposure to the traffic and more likely to walk, proven by how integrated the streets locally. The findings also indicate that low-connected streets can reduce walking distances and accessibility.

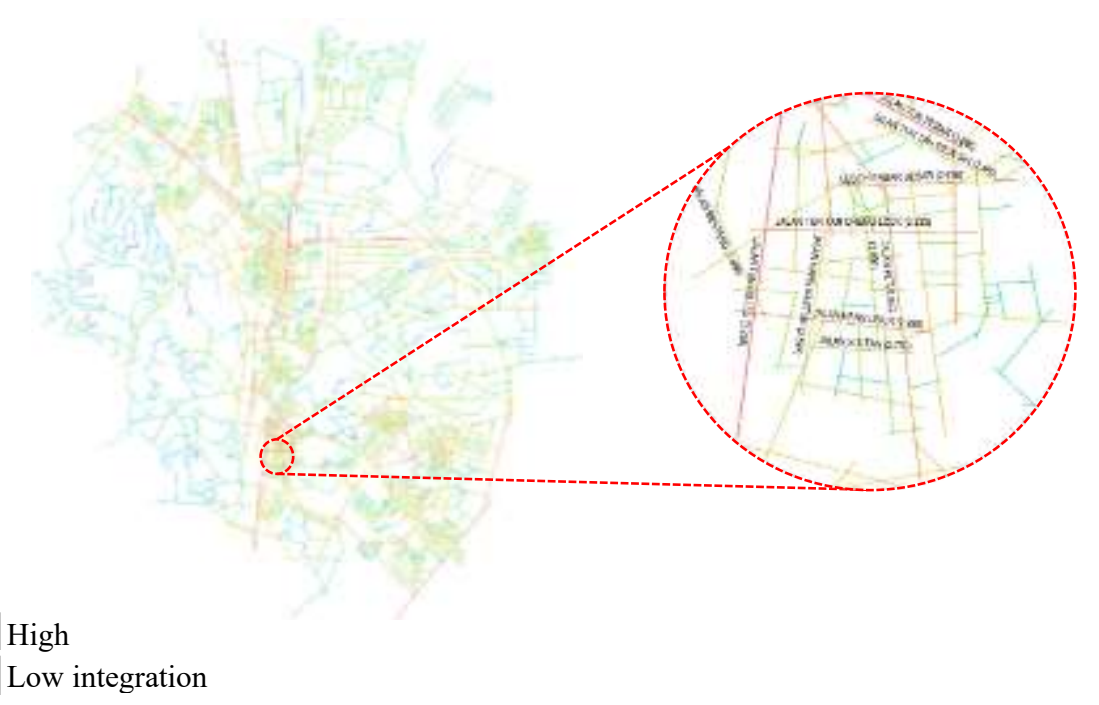

Figure 5: The shorter and fewer axial lines confirm the very distinct morphology of each. 
Nurul Shakila Khalid, Raja Norashekin Raja Othman, Marlyana Azyyati Marzukhi

Public Spaces and Gender: Testing the Relationship of Spatial Configuration of Street Networks

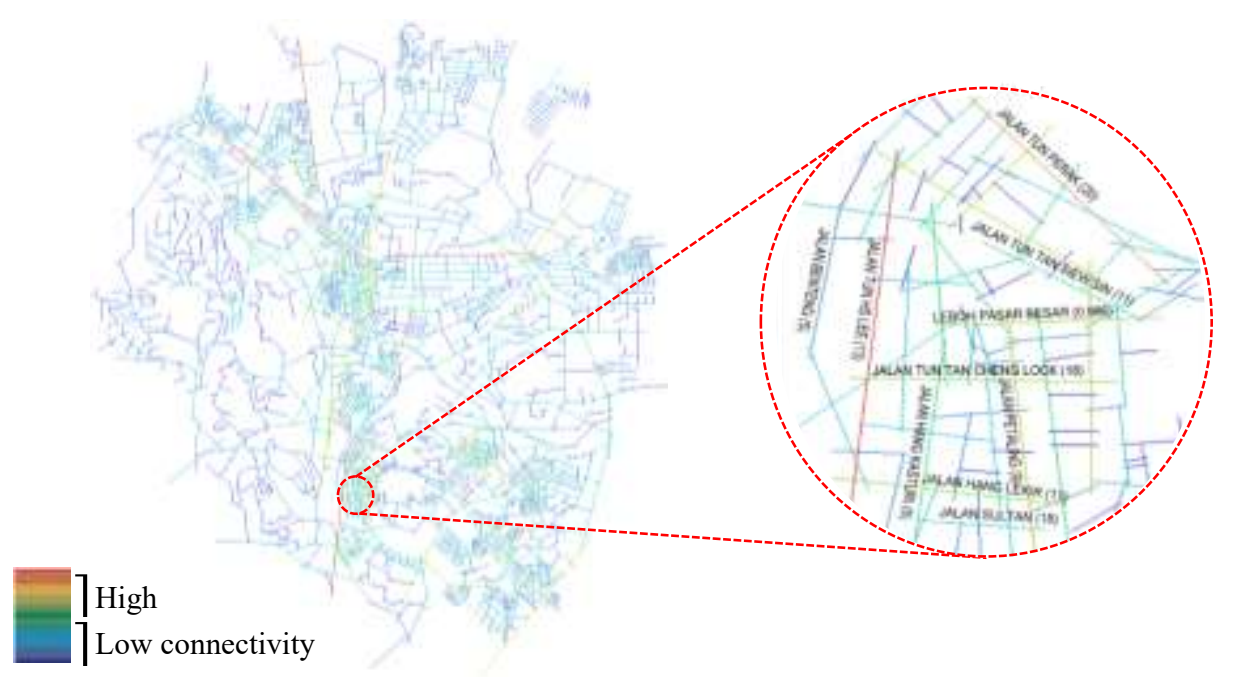

Figure 6: The higher connectivity values are Jalan Tun Perak, Jalan Sultan and Leboh Pasar Besar.

\section{Gendered pedestrians' proportions}

Table 2 present the proportions of total pedestrian, women, and men and how confidence intervals compare between women and men to identify the space uses between genders. The study applied the standard error because interested in the variability of sample means, and the mean is in the centre of the confidence interval. $95 \%$ confidence intervals contain the actual means. If the interval is small, the sample mean must be very close to the true mean. If the confidence interval is extensive, then the sample mean could be very different from the true mean, indicating an inadequate representation of the population.

The result shows that women pedestrians made up proportion 0.35 of weekday users (SE $0.01,95 \%$ CI $[0.39,0.45])$ and 0.38 of weekend users (SE $0.02,95 \%$ CI $[0.55,0.63])$ in Kasturi Walk. Compare to the men pedestrians which score highest mean 0.46 of weekday users (SE $0.02,95 \%$ CI $[0.25,0.29]$ ) and 0.57 of weekend users (SE $0.02,95 \%$ CI $[0.45,0.53]$ ). To be observed, the proportion of women pedestrians was slightly similar between weekdays and weekends, but the proportion of men was largely the difference between weekdays and weekends in Kasturi Walk. It observed that men avoid being in public space during the weekdays compare to women who play a role as a head of household, other than full-time workers.

The differences in proportions of women and men in Petaling Street as weekday and weekend users differed significantly. On weekday, the mean score for women pedestrian is 0.40 (SE $0.01,95 \% \mathrm{CI}[0.70,0.83]$ ) and increased to 0.44 (SE $0.02,95 \% \mathrm{CI}[0.77,0.85]$ ) on weekdays. While men pedestrian recorded 
the mean score 0.51 (SE $0.02,95 \%$ CI $[0.66,0.72]$ ) and increased to 0.66 (SE $0.02,95 \%$ CI $[0.71,0.82]$ ) on weekend. In detail, the differences in proportions of women and males were largely significant in Petaling Street. It was clear that men use public space very differently than women. Moving around in urban public spaces is a collective experience for women and men where different genders have different socio-economic and household roles. Above all, Petaling Street and Kasturi Walk score for integration values are less integrated and highly accessible for pedestrians, which resulted that less integrated streets are attracting more pedestrians.

Table 2: Estimates of the proportion of total pedestrian, women and men by the streets

\begin{tabular}{|l|c|c|c|c|c|c|}
\cline { 2 - 7 } \multicolumn{1}{c|}{} & \multicolumn{2}{l|}{ Weekdays } & \multicolumn{3}{l|}{ Weekends } \\
\cline { 2 - 7 } \multicolumn{1}{c|}{} & Mean & SE & $\mathbf{9 5 \%}$ CI & Mean & SE & $\mathbf{9 5 \% ~ C I ~}$ \\
\hline Total pedestrian & & & & & & \\
• Kasturi Walk & 0.18 & 0.02 & $0.24,0.38$ & 0.31 & 0.02 & $0.69,0.57$ \\
• Petaling Street & 0.27 & 0.02 & $0.77,0.62$ & 0.36 & 0.01 & $0.57,0.62$ \\
\hline $\begin{array}{l}\text { Total women } \\
\text { pedestrian }\end{array}$ & & & & & & \\
• Kasturi Walk & 0.35 & 0.01 & $0.39,0.45$ & 0.38 & 0.02 & $0.55,0.63$ \\
- Petaling Street & 0.40 & 0.01 & $0.70,0.83$ & 0.44 & 0.02 & $0.77,0.85$ \\
\hline $\begin{array}{l}\text { Total men } \\
\text { pedestrian }\end{array}$ & & & & & & \\
• Kasturi Walk & 0.46 & 0.02 & $0.25,0.29$ & 0.57 & 0.02 & $0.45,0.53$ \\
• Petaling Street & 0.51 & 0.02 & $0.66,0.72$ & 0.66 & 0.02 & $0.71,0.82$ \\
\hline
\end{tabular}

\section{Gendered usage in streets}

The highest number of pedestrians has a significant relationship with the duration of stay, whereas the co-presence of attractors in the street offers a variety of goods and businesses that meet the needs of locals and tourists in a convenient environment. It observed that women pedestrians engaged in social activities such as bargaining, shopping, and eating by spending 7 to more than 10 minutes and enabling them to engage with the city freely. Observations in Kasturi Walk discovered on weekdays and weekends highlighted the difference in their duration of stay. On weekdays, pedestrian stayed there for a short length of less than 1-minute compare to in Petaling Street. Conversely, during the weekend, the length of stay increased from less than 1 minute to 5 minutes as the most significant pedestrians among locals and tourists enjoy the sightseeing, lingering, eating, shopping, and appreciating the decorations in Kasturi Walk by taking the photo. Most of them spent more time (in less than 5 minutes) in food stalls compared to the souvenirs shops that sell the key chains, clothing, toys, handcraft, and accessories. They prefer to be in the Central Market due to the scorching hot weather the outside. The narrow space gives the inconvenience for women 
Nurul Shakila Khalid, Raja Norashekin Raja Othman, Marlyana Azyyati Marzukhi

Public Spaces and Gender: Testing the Relationship of Spatial Configuration of Street Networks

pedestrians to stroll with the infant in the stroller. Besides, there is no seating area or benches provided along Kasturi Walk except the seating for the food stalls.

The snapshot observation suggests that women and men pedestrians spend 7 to 10 minutes in Kasturi Walk. However, the majority of them are only passing by the street to the LRT station to the next buildings. Rarely to see the local pedestrians spend minimum time to shop compared to tourists. During the weekday's morning, the number of pedestrians is slightly low because the shops and street vendors are only open at 9.00 am (see Figure $7 \mathrm{~b}$ ). During the lunch hour at $1.00-1.15 \mathrm{pm}$ (see Figure 7c), the pedestrians' concentration is towards Leboh Pasar Besar and more on the left side (beside Central Market), which locates the street vendors and outdoor café. Observation at $5.00-5.15 \mathrm{pm}$ resulted in a similar pattern of pedestrian usage in the morning except for the substantial increasing number of pedestrians (see Figure 7d). The local pedestrians are mostly passing by the street as the office workers started to leave the office, while the tourist pedestrians were strolling along the streets and spending little time to glance.

Table 3: Gender distribution of demographic profiles

\begin{tabular}{|l|c|c|}
\hline & Women (\%) & Men (\%) \\
\hline Age & & \\
-30 & 31.5 & 28.5 \\
-40 & 33.0 & 22.1 \\
$41-50$ & 20.7 & 24.5 \\
$>51$ & 14.8 & 24.9 \\
\hline Ethnicity & 34.5 & \\
Malay & 32.8 & 24.1 \\
Chinese & 15.6 & 40.4 \\
Indian & 17.1 & 10.0 \\
Others & & 25.5 \\
\hline Employment status & 14.1 & \\
Employer & 6.5 & 25.1 \\
Government employer & 25.4 & 3.3 \\
Private employer & 21.0 & 16.5 \\
Self-employed & 22.5 & 26.0 \\
Skilled & 10.5 & 11.2 \\
Unskilled & & 18.0 \\
\hline Nationality & 52.0 & \\
Malaysian & 48.0 & 40.5 \\
Non-Malaysian & & 59.5 \\
\hline
\end{tabular}

The mapping also shows the majority of women pedestrian in Kasturi Walk using this space by herself. They comfortable in being alone, and this category of women pedestrians are usually a passer-by pedestrian who use the 
space daily, and very familiar with the surroundings. Likewise, to a leisurepedestrian, either local woman or tourist at the age of 15 to 40 , they always accompanied by partners, friends, or family and spending more time in the space.

On weekday's evening, Petaling Street shows the different patterns of pedestrian usage space, as shown in Figure 7a. The pedestrian's space usage pattern is intense at the intersection of Jalan Hang Lekir, which connects pedestrians to Jalan Tun HS Lee and Jalan Sultan and at the entrance of Petaling Street. Additionally, all the famous local foods and drinks such as soya bean milk, tau-fu-fah, and fresh fruits and vegetables are available in the market until $6 \mathrm{pm}$ every day, makes it convenient for the daily life of urban residents.

Petaling Street is also known for its pickpocket and security issues. This street is infamous for the numbers of aggressive between groups of overseeing the territorial, homeless and beggars. These factors have resulted in constant surveillance through CCTV, and Police and enforcement officers patrolling. Women are not seen using the space by themselves, especially in the early mornings or late evenings, as there are fewer people around. Most of the business except the market is open at $10.00 \mathrm{am}$. Besides, most of the shop owners of imitation items and storekeepers are Chinese men and foreign workers-contribute to the unpleasant experience among women pedestrians.

The women pedestrians who walk alone in Petaling Street, especially on weekdays averagely, are elderly (the 40 s and above) due to the familiarity with the area compared to women pedestrians in Kasturi Walk, who are mostly working (see Figure 8). Other than elder women pedestrians, large clusters of youth in pairs and groups (average aged below 30) dominated this space on weekends. The foods and the "branded items" are the major attractions for families and youth to come to Petaling Street. 
Nurul Shakila Khalid, Raja Norashekin Raja Othman, Marlyana Azyyati Marzukhi

Public Spaces and Gender: Testing the Relationship of Spatial Configuration of Street Networks
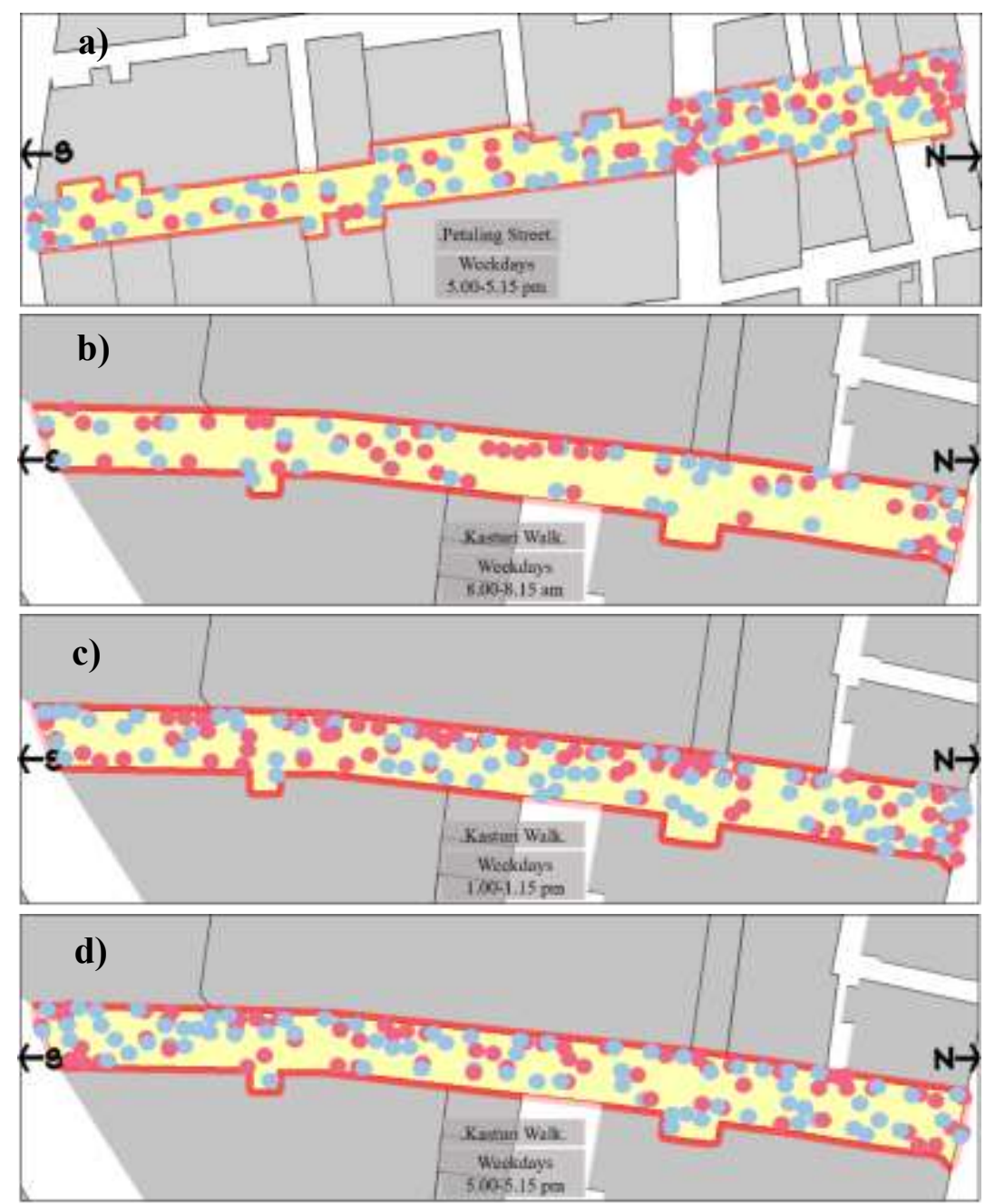
Men
Women

Figure 7: Gendered use space in Petaling Street and Kasturi Walk on weekdays.

By attaching configurational measurements to each street segment in the study areas, the relationship between pedestrian behaviours among men and women, and those measurements of integrations can be examined. The evidence to date has focused mainly on the presence of activity on the streets, finding that high local integration streets have a higher number of pedestrians and provide a better quality of space. 


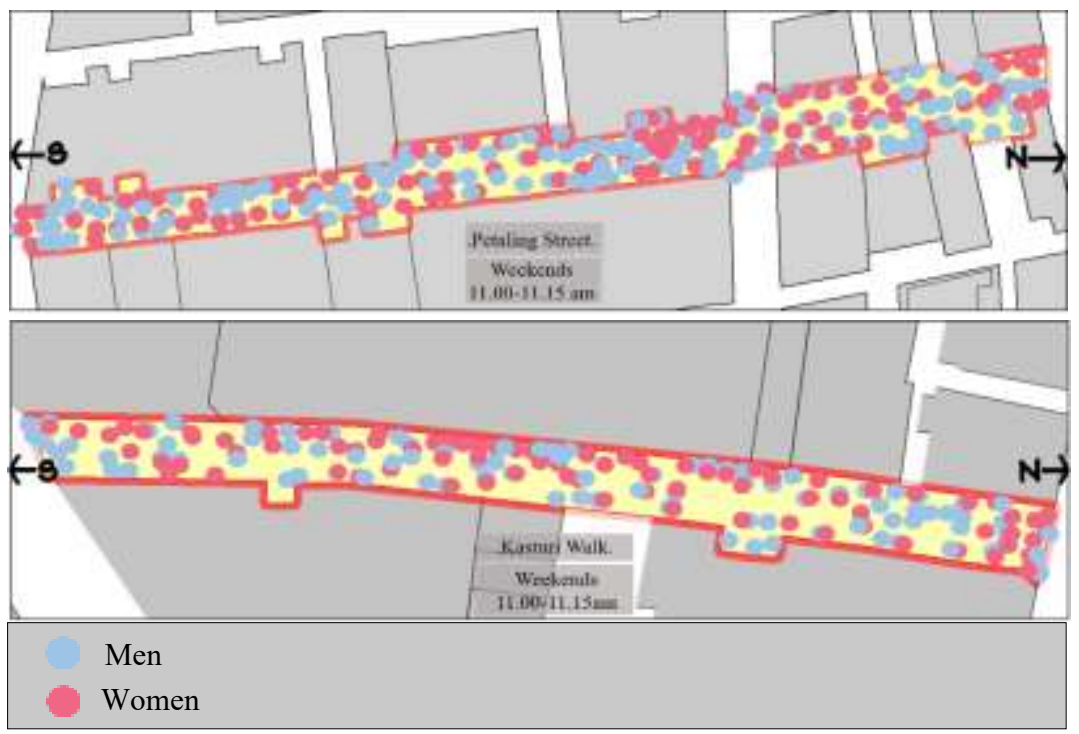

Figure 8: Gendered use space in Petaling Street and Kasturi Walk on weekends.

\section{DISCUSSION}

The measures of street integration-global and local provide significant relationships with pedestrian movement and activity within the space. The findings found that the local integration associated with the number of pedestrians and duration of stay while global integration was correlated with vehicle movement. In this research, the integrated street draws more people and enhance more trips. The local integration value of the Kasturi Walk is slightly lower compared to the integration of Petaling Street. More pedestrians make walking trips to Petaling Street and spend a long time carrying various social activities. Most of the social activity occurred in the intersections of Jalan Hang Lekir, where there has a morning market.

The proportion of men and women pedestrians also shows a similar number, but different age background. More local integrated streets such as Petaling Street is accessible for pedestrians from other streets likely to attract more women pedestrians. The vibrant activity in Petaling Street also becomes the attractor to the pedestrian in everyday urban life. However, several factors, such as safety and men dominant space, contribute to the unpleasant experience unless the women pedestrians accompanied by partners, friends, or family, or walk in a group. The feeling of unsafe or inconvenient in the crowded space may influence by the presence of many people, patrolling by the police, and the small-scale commercial activity along the streets. The feeling thus creates an experience of 
Nurul Shakila Khalid, Raja Norashekin Raja Othman, Marlyana Azyyati Marzukhi

Public Spaces and Gender: Testing the Relationship of Spatial Configuration of Street Networks

how women in that space. The findings show that women's experience in public spaces is different from men's, mainly when men dominate the area.

In contrast to the pedestrian patterns in Kasturi Walk, which is scored slightly higher global integration value than Petaling Street, it shows fewer pedestrians, especially among women and they only use space in a row of street vendors and outdoor cafes (besides the Central Market) rather than the row in front of the old shophouses in Jalan Hang Kasturi. The roles of the Kasturi Walk can be argued. The transformation of enhancing the image of Kasturi Walk for passing-by street to Central Market or other adjacent streets, a place for shade with proper ventilation, or it is for tourists only when it failed to attract the local pedestrians? The less integrated street encourages fewer people to present in a shorter duration of stay.

The results of the proportion between women and men in uses of public spaces show that many factors influence the presence of women; a variety of goods and services, a group of users, accessibility and walkability, and convenient. Besides, their presence much depends on their purpose to come to the streets-women, and men likely have different purposes, such as for leisure, sightseeing, eating, and buy groceries. However, most of the shop owners and shop assistants in Petaling Street are men. To compare the range of activities and goods in both streets, Petaling Street is the preferable place to visit by women. When the street offers a variety of products, it will consequently encourage social engagement and social exchange. The pattern of activities taking place in the streets justifies that people intuitively re-configures the space for their best uses. 


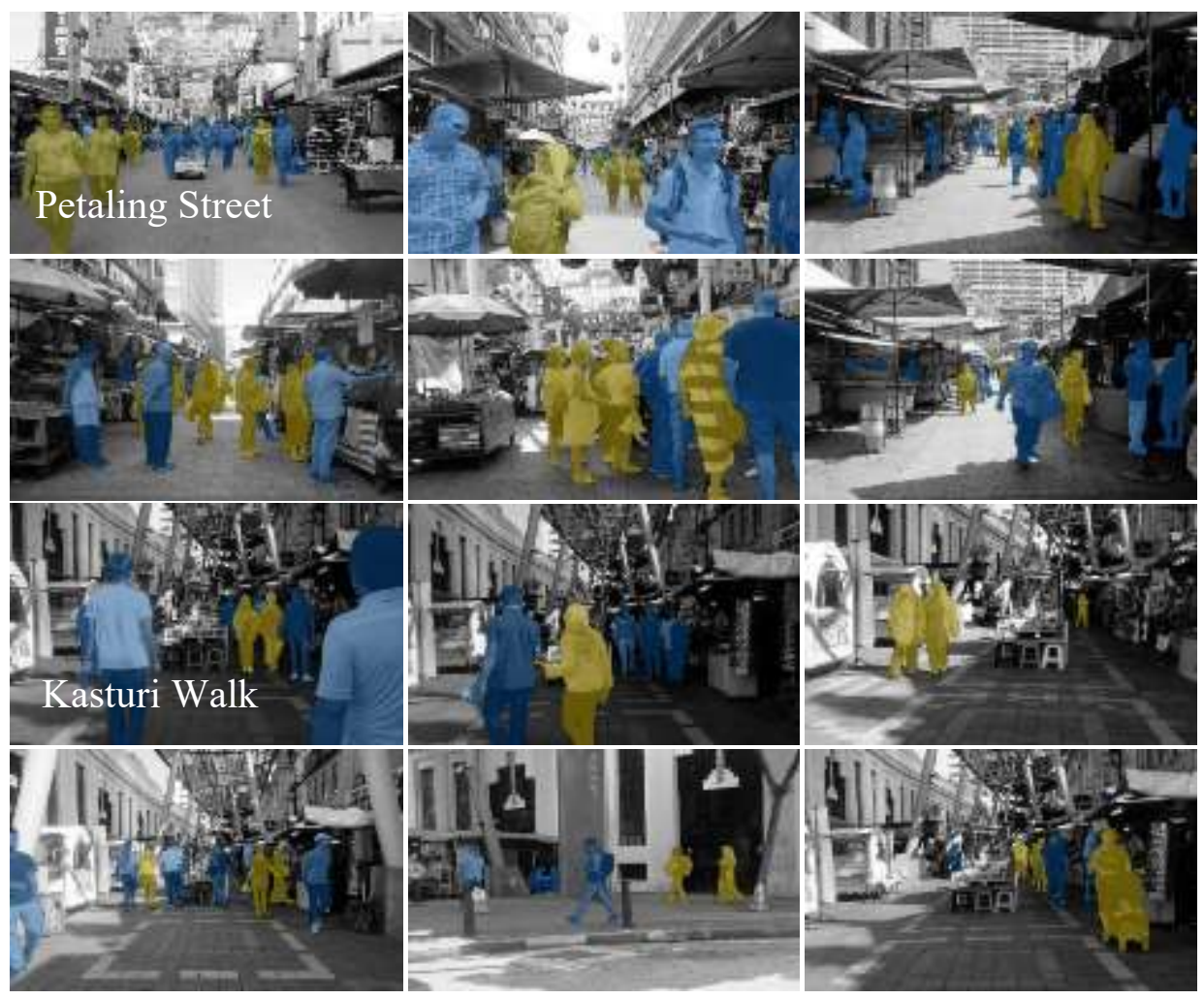

Figure 9: Documenting a photograph in Petaling Street and Kasturi Walk enable the researcher to interpret the pedestrian's experience in the streets.

\section{CONCLUSION AND RECOMMENDATIONS}

Public spaces should be genuinely 'public' and democratic. They must be accessible to everyone throughout the day. To emphasize public space terms, this means that the right to the city of every population regardless of gender, ethnicity, nor religion must be protected. A successful public space is one where users of different backgrounds can coexist without one group dominating another. The city or public space can belong to women when it pertains to everyone. In this sense, space syntax is useful to provide a better understanding of the role of the street network in supporting public life because it deals with both spatial and functional aspects of street space. This research suggests the further research to understand the street network patterns; the structured observation that carried in this research could not answer the vital question about how democratic and equitable the streets are, of who might benefit most, who "own" space, or who will avoid the street and why. Besides, the research findings are expecting to help city managers, and urban designers to actively constructing ideas of what it means to embrace the visibility of women in public space. 
Nurul Shakila Khalid, Raja Norashekin Raja Othman, Marlyana Azyyati Marzukhi

Public Spaces and Gender: Testing the Relationship of Spatial Configuration of Street Networks

The application of space syntax in examining the spatial configuration of the pedestrian in a city makes it as a baseline study. The integration value allows two propose interventions; (i) to identify potential streets to transform regarding accessibility, and (ii) to design spatial interventions where the street associated with the present low integration values. If the values are increasing, the attraction to public spaces will be increasing.

\section{ACKNOWLEDGEMENTS}

The research has been done under the funding of Universiti Teknologi MARA and Lestari Grant 600-IRMI 5/3/Lestari (040-2018).

\section{REFERENCES}

Arjmand, R. (2016). Public Urban Space, Gender and Segregation: Women-Only Urban Parks in Iran. Routledge.

Bafna, S. (2003). Space Syntax: A Brief Introduction to its Logic and Analytical Techniques. Environment and Behavior, 35(1), 17-29.

Beebeejaun, Y. (2017). Gender, Urban Space, and the Right to Everyday Life. Journal of Urban Affairs, 39(3), 323-334.

Cheshmehzangi, A., and Heat, T. (2012). Urban Identities: Influences on SocioEnvironmental Values and Spatial Inter-Relations. Procedia-Social and Behavioral Sciences, 36, 253-264.

Doan, P.L. (2010). The Tyranny of Gendered Spaces-Reflections from Beyond the Gender Dichotomy. Gender, Place \& Culture, 17(5), 635-654.

Francis, M. (2016). The Making of Democratic Streets. Contesti. Città, Territori, Progetti, (1-2), 192-213.

Fenster, T. (2005). The Right to the Gendered City: Different Formations of Belonging in Everyday Life. Journal of Gender Studies, 14(3), 217-231.

Goodsell, C. T. (2003). The Concept of Public Space and Its Democratic Manifestations. American Review of Public Administration, 33(4), 361-83.

Hajrasouliha, A., and Yin, L. (2015). The Impact of Street Network Connectivity on Pedestrian Volume. Urban Studies, 52(13), 2483-2497.

Hillier, B., and Hanson, J. (1989). The Social Logic of Space. Cambridge University Press.

Hillier, B. (2007). Space Is the Machine: A Configurational Theory of Architecture. Space Syntax.

Hillier, B., Penn, A., Hanson, J., Grajewski, T., and Xu, J. (1993). Natural Movement: or, Configuration and Attraction in Urban Pedestrian Movement. Environment and Planning B: Planning and Design, 20(1), 29-66.

Khalili, A., Fallah, S. N., Mohamad Rasdi, M. T., Farzin, A. A., and Mansouri, S. A. (2015). Conduciveness of Women Social Setting in Traditional Iranian Bazaar from Functional Dimension. Asian Social Science, 11(12), 297. 
Ling, O. H. L., Nik Nurul Farahanis, M. S., Farah Ayuni, M., Siti Nur Afiqah, M. M. (2017). Social Impact of Foreign Immigrants in Affordable Housing Area. Case study: Mentari Court, Selangor, Malaysia. Planning Malaysia 15 (2), 37-50.

Ling, O. H. L., Nur Hidayah, S., Marlyana, A.M., Sharifah Zannierah, S.M. (2018). Healthy Lifestyle of Urban Residents. Case Study: Sri Pahang Public Housing, Bangsar, Kuala Lumpur, Malaysia. Planning Malaysia 16 (3), 1-12.

Mahadevia, D., and Lathia, S. (2019). Women's Safety and Public Spaces: Lessons from the Sabarmati Riverfront, India. Urban Planning, 4(2), 154-168.

Mehta, V., and Bosson, J. K. (2010). Third Places and the Social Life of Streets. Environment and Behavior, 42(6), 779-805.

Mehta, V. (2013). The Street: A Quintessential Social Public Space. Routledge.

Sassen, S. (1996). Analytic borderlands: race, gender and representation in the new city. In Re-presenting the City (pp. 183-202). Palgrave, London.

Souza, A. C. S., Bittencourt, L., and Taco, P.W.G. (2018). Women's Perspective in Pedestrian Mobility Planning: The Case of Brasília. Transportation Research Procedia, 33, 131-138.

Tandogan, O., and Ilhan, B. S. (2016). Fear of Crime In Public Spaces: From The View of Women Living In Cities. Procedia Engineering, 161, 2011-2018.

UN-HABITAT (2010) Gender Equality for Smarter Cities: Challenges and Progress (Nairobi:

UN-HABITAT). (http://www.unhabitat.org/pmss/listItemDetails.aspx?publicationID=2887).

Wala Hashim Bashari, D., Mirghani, A. H., and Bahreldin, I. Z. (2015). Spatial Impact of Gender Variation on Khartoum City River Side Public Open Space. Urban Development.

Zavestoski, S., and Agyeman, J. (Eds.). (2014). Incomplete Streets: Processes, Practices, and Possibilities. Routledge.

Received: $15^{\text {th }}$ May 2020. Accepted: $1^{\text {st }}$ Sept 2020 